\title{
Influence of root canal sealer on the radiographic appearance of filling voids in maxillary single- rooted teeth
}

\author{
Augusto BODANEZI' ${ }^{1}$ Etiene Andrade MUNHOZ², Ana Lúcia Álvares CAPELOZZA 3 , Norberti BERNARDINELI', Ivaldo \\ Gomes de MORAES ${ }^{4}$, Roberto Brandão GARCIA ${ }^{5}$, Clovis Monteiro BRAMANTE ${ }^{4}$
}

\begin{abstract}
1- DDS, MSc, PhD, Professor of Endodontics, Department of Conservative Dentistry, School of Dentistry, Federal University of Rio Grande do Sul, RS, Brazil. 2- DDS, MSc,PhD, Adjunct Professor of Pathology, Department of Conservative Dentistry, School of Dentistry, Federal University of Rio Grande do Sul, RS, Brazil. 3- DDS, MSc, PhD, Associate Professor of Radiology, Department of Radiology, Stomatology and Oral Surgery, Bauru School of Dentistry, University of São Paulo, Bauru, SP, Brazil.

4- DDS, MSc, PhD, Full Professor of Endodontics, Department of Operative Dentistry, Endodontics and Dental Materials, Bauru School of Dentistry, University of São Paulo, Bauru, SP, Brazil.

5- DDS, MSc, PhD, Associate Professor of Endodontics, Department of Operative Dentistry, Endodontics and Dental Materials, Bauru School of Dentistry, University of São Paulo, Bauru, SP, Brazil.
\end{abstract}

Corresponding address: Dr. Augusto Bodanezi - Faculdade de Odontologia da UFRGS - Departamento de Odontologia Conservadora - Endodontia - R. Ramiro Barcelos, 2492 - 90035-0073 - Porto Alegre - RS - Brazil - Phone: 5133085430 - Fax: 5133165197 - e-mail: augusto.bodanezi@ufrgs.br

Received: July 11, 2010 - Modification: August 16, 2011 - Accepted: October 1, 2011

\section{ABSTRACT}

\begin{abstract}
Od bjective: This study compared the influence of three epoxy resin-based sealers with distinct radiopacities on the observers' ability to detect root canal filling voids during radiographic analysis. Material and methods: The root canals of 48 extracted maxillary canines were prepared and divided into three groups. Each group was laterally condensed with one sealer (AH Plus ${ }^{\mathrm{TM}}$, Acroseal ${ }^{\circledR}$ or a non-radiopaque sealer), and a longitudinal void was simulated in half of the specimens from each group $(n=8)$. Buccolingual radiographs were obtained and randomly interpreted for voids by a radiologist and an endodontist in a blinded fashion. Teeth were cut and inspected under a microscope to confirm the position of void. Differences in sensitivity and specificity between groups and examiners were compared using the Fisher's Exact and McNemar tests, respectively $(\alpha=0.05)$. Results: Significantly lower sensitivity levels $(p<0.05)$ were observed in the coronal portion of fillings performed with both radiopaque sealers. Specificity values for Acroseal ${ }^{\circledR}$ were significantly higher $(p<0.05)$ in the coronal and apical portions of fillings. Conclusions: The type of root canal sealer can affect the observers' ability to detect root canal filling voids during radiographic analysis of upper single-rooted teeth.
\end{abstract}

Key words: Epoxy resins. Radiography. Root canal filling materials. Root canal obturation. Sensitivity and specificity.

\section{INTRODUCTION}

The assessment of root canal therapy in order to determine whether retreatment is needed constitutes a frequent and difficult task for clinicians, especially when patient's signs and symptoms are not evident ${ }^{21}$.

Conventional periapical radiography is the most commonly used method for evaluating the technical quality of filled root canals ${ }^{10}$. Buccolingual radiographs are generally accepted to have limited value for root canal quality assessments ${ }^{12,20}$.
Nevertheless, since this is the only objective noninvasive method for assessing root canal fillings, current evidence on endodontic treatment outcome is solely derived from follow-up studies that rely basically on this method $7,14,16$.

Root canal fillings can be distinguished on radiographs because the sealing materials must have some degree of radiopacity, provided that it is above that of dentin and bone $e^{2,4}$. As the sealer is used together with gutta-percha for root canal filling, its type and thickness may have a significant effect on the radiographic appearance of the obturated 
canal $^{3,10}$. It is postulated that the use of a sealer with greater radiopacity might give the impression of a compact filling, despite the presence of gross imperfections. On the other hand, a less radiopaque material might be judged absent in areas where it is actually present in small amounts ${ }^{4,9}$. Among the resin-based sealers commercially available, results from recent in vitro investigations indicate that $\mathrm{AH}$ Plus is twice as radiopaque as Acroseal ${ }^{\circledR 18,19}$.

Radiographic void detection is clinically important for prognosis determination since cross-sectional investigations have correlated the presence of filling voids with apical periodontitis ${ }^{7,14}$. Therefore, this study aimed to investigate if any of two radiopaque resin-based sealers blurred the observers' ability to detect root canal filling voids during radiographic analysis.

\section{MATERIAL AND METHODS}

\section{Tooth preparation}

For this study, 48 permanent maxillary canines with single straight or slightly curved root canals $(25 \pm 2 \mathrm{~mm}$ ) were selected and stored in $0.5 \%$ saline solution after approval of the research project by the University of São Paulo's Research Ethics Committee (Protocol \#153/2005). After standard access, root canal lengths were assessed by placing a size 15 $K$ file (Dentisly, Dentsply/Maillefer, Ballaigues, Switzerland) inside the canal until the tip perforated through the apical foramen. The instrument was withdrawn $1 \mathrm{~mm}$ to record the working length. All canals were instrumented using a push-pull filing technique up to file size 55. After every instrument withdrawal from the root canal, full irrigation with $1 \%$ sodium hypochlorite was performed.

Apical foramen enlargement was done with a 25 $\mathrm{K}$ file. After a 3-min final irrigation with 17\% EDTA (Biodinâmica, Biodinâmica Química e Farmacêutica Ltda., Ibiporã, PR, Brazil), the root canals were rinsed with $0.5 \%$ saline and dried thoroughly with paper points.

The samples were divided into three groups, and each group was laterally condensed with one of the following epoxy resin-based sealers: $\mathrm{AH}$ Plus $^{\mathrm{TM}}$ (Dentsply, Dentsply DeTrey Gmbh, Konstanz, Germany), Acroseal ${ }^{\circledR}$ (Septodont, Specialités Septodont, Saint-Maur-des-Fossés, France) and an experimental non-radiopaque sealer (NRS) used as a control.

$\mathrm{AH}$ Plus $^{\mathrm{TM}}$ and Acroseal ${ }^{\circledR}$ were measured and mixed at a ratio of $1: 1$ paste/paste, according to the manufacturer's recommendations. For the experimental NRS, 1 part of catalyst (resin hardener) was added to 2 parts of resinous base (epoxy resin and polyurethane polyol), and then the mixture was homogenized for $15 \mathrm{~s}$.

Before being filled with lateral condensation, a radiolucent nylon fishing line $(0.25 \mathrm{~mm}$ in diameter and $20 \mathrm{~cm}$ in length) (Tople On ${ }^{\circledR}$, Tople, Hong Kong, China) was inserted into the root canal of half of the specimens of each group $(n=8)$. Both ends of the string were tied in alignment to a device, such that moving the tooth distally would put the stretched fishing line into contact with the mesial wall of the root canal through the entire filling procedure.

The sealer was taken to the root canals by coating the appropriate master gutta-percha cone. A \#30 master cone was used in root canals that received the nylon thread, whereas a \#55 master cone was inserted into the remaining root canals. The master cone was laterally condensed with $A$ and B finger spreaders (Dentsply, Dentsply-Maillefer, Ballaigues, Switzerland), and 7-9 accessory cones (Tanari R7, Tanari ${ }^{\circledR}$, Manacapuru, AM, Brazil) were added. After obturation, coronally extruded excess sealer and gutta-percha were cleaned. All filling procedures were conducted by a single operator with five years of clinical experience in endodontics. This operator was instructed to perform eight fillings per day.

\section{Radiographic procedure}

Radiographs of each canine were obtained in the buccolingual direction using the paralleling technique. The tooth was fixed into the canine bone alveolus of a phantom built from a dry human maxilla acrylic-coated for soft tissue simulation. Each periapical E film (Insight; Kodak Co., Rochester, NY, USA) was maintained in a constant position during radiographic exposure through insertion in the acrylic slot shaped in the vault of the palate.

The phantom was positioned in front of the X-ray tube with a specifically designed resinous device. All radiographic exposures were completed with a dental X-ray unit (X 70; Dabi Atlante, Ribeirão Preto, SP, Brazil) at $70 \mathrm{kVp}$ and $8 \mathrm{~mA}$. The exposure time was $0.5 \mathrm{~s}$, the focus-object distance was 40 $\mathrm{cm}$ and the object-to-receptor distance was $2 \mathrm{~cm}$.

In a darkened room with temperature set at $21^{\circ} \mathrm{C}$ the exposed films were immersed together in the developer solution for $3 \mathrm{~min}$ at $21^{\circ} \mathrm{C}$ and then rinsed with water for $10 \mathrm{~s}$ before being submerged in the fixer solution for $8 \mathrm{~min}$. The developed films were subsequently washed with running water for $10 \mathrm{~min}$ and allowed to dry in a dust-free atmosphere.

To assure the same position of the fishing line for all teeth, the roots were sectioned transversely with a 0.3-mm-thick diamond saw (IsoMet $15 \mathrm{HC}$, Buehler, Buehler, Lake Bluff, Illinois, USA) at 300 rpm and the three resulting sections observed under magnification to confirm the mesial position of the nylon string (Figure 1 ) and the absence of major voids in those teeth without artificial defect. Nine 
sectioned specimens in which the fishing line was not in the expected position or presented major inherent voids were replaced.

\section{Image evaluation}

Prior to image interpretation, a radiologist and an endodontist, who had not performed any of the fillings, received written instructions about the test. The examiners were asked to scrutinize radiographic images for the presence of voids in the mesial, middle and distal aspects of the root canal fillings, which were divided imaginatively and equally into coronal, medium and apical thirds for organizational purposes. No information on filling preparation was provided, and examiners were instructed to ignore the distance of fillings to the apex or any radiolucent area in contact with the

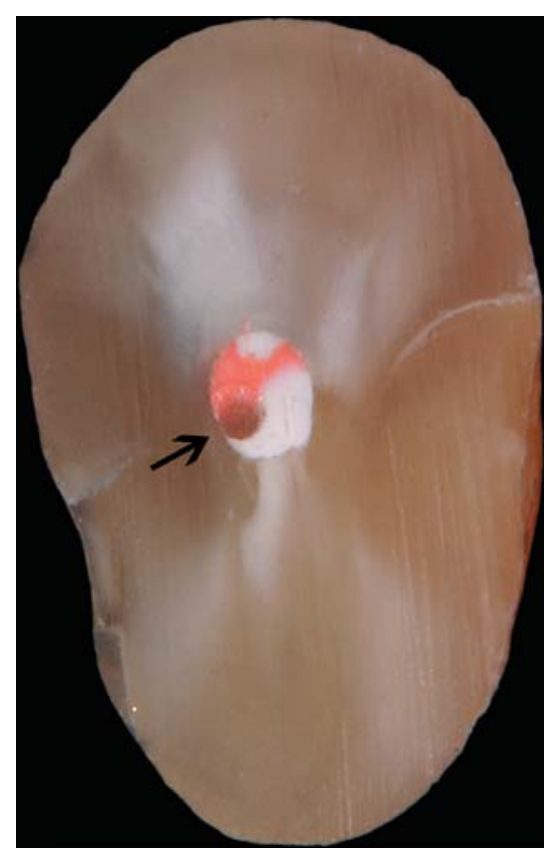

Figure 1- Apical cross section of the root canal filling showing the nylon thread used to simulate the void (arrow) root.

Immediately after, a pair of radiographs with non-defective and defective fillings served as models to demonstrate the appearance of voids to the examiners.

All radiographic assessments were performed with the aid of an ethyl-vinyl-acetate mask positioned over a fluorescent cold lightbox (Medalight LP-400, Hong Kong, China) in the same light-controlled room. The 48 radiographs were numbered, mounted in a random order and individually interpreted (Figure 2). The observers had no knowledge of the extent, location or distribution of the voids.

Analyses of images were recorded in a proper form, and the viewing time was unlimited. A second evaluation was undertaken 4 weeks after the first assessment.

\section{Statistical analysis}

Sensitivity refers to the proportion of root canal fillings correctly identified as having a defect among a group of fillings that really had a simulated defect. To calculate sensitivity, the mean number of defective fillings correctly identified for each group in both evaluations was divided by the mean number of defective fillings correctly identified (true positives) plus the mean number of false negative results.

Specificity refers to the proportion of root canal fillings correctly detected as not having a defect among a group of fillings that did not have simulated defects. Specificity of each group was determined by the mean number of non-defective fillings correctly identified divided by the mean number of non-defective fillings correctly identified (true negative) plus false positive results.

The differences in sensitivity and specificity values between groups and examiners were compared using Fisher's Exact and McNemar's tests, respectively, which were both adjusted to the $95 \%$

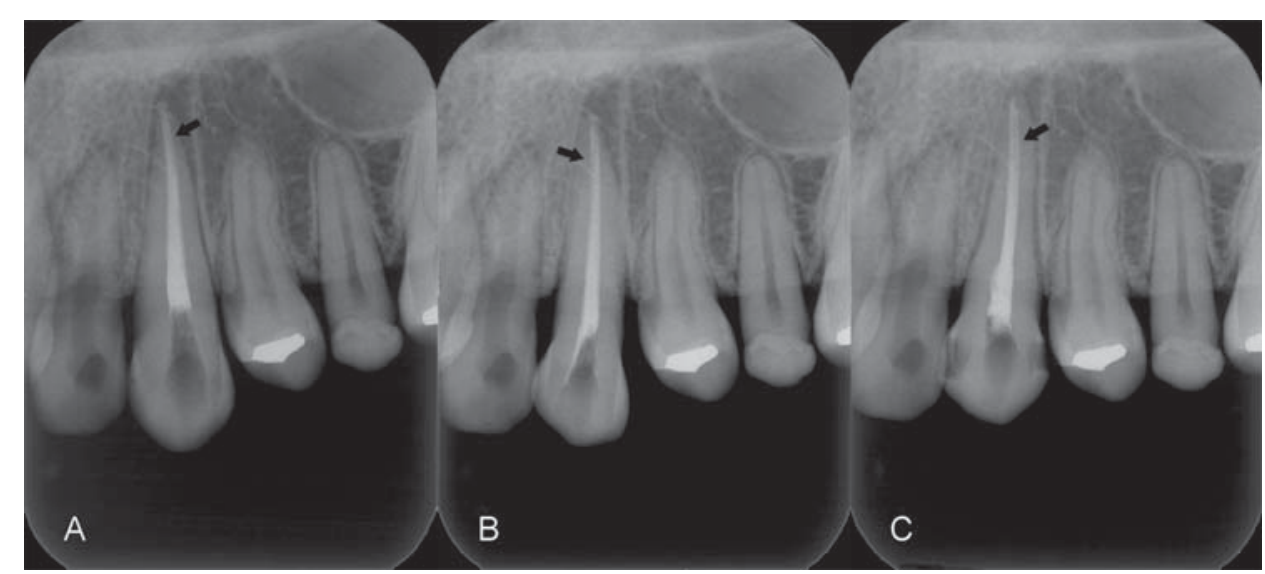

Figure 2- Representative radiographic images of defective root canal fillings assessed by the examiners $\left(A-A H P l u s^{\mathrm{TM}}\right.$; $\mathrm{B}-$ Acroseal $^{\circledR}$; C - Non-radiopaque sealer). Note the appearance of simulated voids (arrows) 
Table 1- Mean values and ranges of sensitivity in each third of the fillings assessed by the examiners (same letters indicate statistically significant difference at $5 \%$ )

\begin{tabular}{ccccc}
\hline Sealer & Specialty & Coronal & Middle & Apical \\
\hline AH Plus $^{\mathrm{TM}}$ & Endod. & $0.51(0.63-0.38)^{\mathrm{a}}$ & $0.88(0.88-0.88)^{\mathrm{f}}$ & $1.00(1.00-1.00)^{\mathrm{a}}$ \\
& Radiol. & $0.12(0.25-0.00)^{\mathrm{b}}$ & $0.38(0.63-0.13)^{\mathrm{f}}$ & $0.81(0.88-0.75)^{\mathrm{b}}$ \\
Acroseal $^{\circledR}$ & Endod. & $0.50(0.75-0.25)^{\mathrm{c}}$ & $0.75(0.88-0.63)$ & $1.00(1.00-1.00)^{\mathrm{c}}$ \\
& Radiol. & $0.06(0.13-0.00)^{\mathrm{d}}$ & $0.44(0.50-0.38)$ & $0.75(1.00-0.50)^{\mathrm{d}}$ \\
NRS & Endod. & $0.82(1.00-0.63)^{\mathrm{abcdf}}$ & $0.69(0.75-0.63)$ & $0.94(1.00-0.88)$ \\
& Radiol. & $0.19(0.38-0.00)^{\mathrm{ef}}$ & $0.44(0.63-0.25)$ & $0.75(0.88-0.63)^{\mathrm{e}}$ \\
\hline
\end{tabular}

Table 2- Mean values and ranges of specificity in each third of the fillings assessed by the examiners (same letters indicates statistically significant difference at $5 \%$ )

\begin{tabular}{ccccc}
\hline Sealer & Specialty & Coronal & Middle & Apical \\
\hline AH Plus $^{\mathrm{TM}}$ & Endod. & $0.75(0.63-0.87)$ & $0.81(0.87-0.75)$ & $0.81(0.62-1.00)$ \\
& Radiol. & $0.87(0.75-1.00)$ & $0.81(0.75-0.87)$ & $0.68(0.50-0.87)$ \\
Acroseal $^{\circledR}$ & Endod. & $0.87(0.87-0.87)$ & $1.00(1.00-1.00)$ & $0.94(0.88-1.00)^{\mathrm{a}}$ \\
& Radiol. & $1.00(1.00-1.00)^{\mathrm{c}}$ & $1.00(1.00-1.00)$ & $1.00(1.00-1.00)^{\mathrm{b}}$ \\
\multirow{2}{*}{ NRS } & Endod. & $0.50(0.38-0.62)$ & $0.75(0.63-0.87)$ & $0.62(0.38-0.87)^{\mathrm{a}}$ \\
& Radiol. & $0.62(0.25-1.00)^{\mathrm{c}}$ & $0.94(0.87-1.00)$ & $0.62(0.38-0.87)^{\mathrm{b}}$ \\
\hline
\end{tabular}

confidence interval. The intra-observer agreement was determined by Cohen's Kappa statistic. Statistical evaluation for all tests was performed with SPSS database software (SPSS v.11.0, SPSS Inc., Chicago, IL, USA).

\section{RESULTS}

\section{Sensitivity}

In the assessment by the endodontist, the experimental groups had significantly lower sensitivity values $(p<0.05)$ than the NRS group (control) at the coronal third of the root canal fillings (Table 1). The coronal portion of $\mathrm{AH}$ Plus ${ }^{\mathrm{TM}}$ and Acroseal ${ }^{\circledR}$ fillings exhibited significantly lower sensitivity values $(p<0.05)$ than the apical portion for both examiners. In the control group, this difference was only observed in the assessment by the radiologist. In comparison with the radiologist's examination, significantly higher sensitivity values $(p<0.05)$ for the endodontist's evaluation of the NRS (cervical portion) and AH Plus (middle portion) groups were noted. The sensitivity values obtained in the middle portion of the root canal fillings were not significantly different from those obtained in the coronal and apical portions ( $p>0.05)$.

\section{Specificity}

In the radiologist's evaluation, the coronal and apical portions of Acroseal fillings exhibited significantly higher values of specificity $(p<0.05)$ than the NRS group (control), whereas the endodontist's assessment revealed significant differences $(p<0.05)$ only for the apical portion (Table 2). For all groups, the differences in specificity between the coronal and apical portions of the root canal fillings were not statistically significant ( $p>0.05)$, nor were the specificity values obtained in the middle portion in comparison to the coronal and apical thirds ( $p>0.05)$.

\section{Intraobserver agreement}

The intraobserver Kappa values were 0.71 for the radiologist and 0.77 for the endodontist.

\section{DISCUSSION}

The present study is the first to investigate the radiographic sensitivity and specificity of laterally condensed root canal fillings. The use of a nylon string to simulate an empty space inside half of the root canals from each group permitted some standardization of the thickness, position and even apical extension of the void through the entire filling, which is a characteristic nearly impossible to control in clinical studies 7,17 . Given that a long radiolucent line is not a usual pattern of laterally condensed root canal filling defects, different results should be expected when a more realistic void simulation method is developed.

The thickness of $0.25 \mathrm{~mm}$ for the simulated void was chosen on the basis of prior investigations in which this diameter was considered the threshold to decide whether a root canal obturation was well 
or poorly condensed ${ }^{12,20}$. Huybrechts, et al. ${ }^{11}$ (2009) observed that analogue intraoral radiographs were ineffective for the detection of voids $0.20 \mathrm{~mm}$ in diameter. Given the large number of simulated defects correctly identified in this study, it could be inferred that the thinnest detectable diameter for filling voids in canine teeth is between 0.20 and 0.25 $\mathrm{mm}$, at least with this imaging technique.

Because $a$ thin and long radiolucent line is not a usual pattern in radiological images of obturated root canals, viewers might have not perceived it as a void despite prior training with defective and non-defective models. In addition, since the simulated defect was, at most, close to the mesial root canal wall, it is possible that the similarities between the low radiographic densities of control group fillings and dentin at the interface may have smothered the radiolucent void appearance and therefore misled the observers (background density effect $)^{16}$. These circumstances could justify the large number of false negative results and consequently the low sensitivity levels for the radiologist during assessment of the coronal and middle portions of artificial defective fillings.

In the radiographic assessment of laterally condensed root canal fillings, some false positive results may originate from visualization of multiple voids either inherent to lateral condensation or caused by imperfections in the filling procedure ${ }^{8}$. To estimate this bias, a non-radiopaque sealer was used to complete the fillings, and the mean specificity value obtained (0.73) was comparable to that described by Kositbowornchai, et al. ${ }^{13}$ (2006) for single cone fillings (0.80). Although the examiners of both studies were experienced radiologists, the radiographic superimposition caused by the mineralized maxillary trabeculae (reproduced in this study) may have impaired the identification of procedural voids ${ }^{20}$. Moreover, in the experimental fillings devoid of simulated defects, the abrupt changes in optical densities between the filling and the dentin may have generated the illusion of lateral radiolucent longitudinal lines that were possibly misdiagnosed as voids by the examiners (mach band phenomenon) ${ }^{15}$ and, thus, may account for some of the false positive results observed.

According to our data, the use of both radiopaque sealers caused an equivalent reduction of radiographic sensitivity that was significant in the coronal portion of the fillings and, to a less extent, in the middle third as well (Table 1 ). It is possible that the simulated void was hidden by radiographic superimposition resulting from the thicker mass of gutta-percha in addition to sealer accumulation ${ }^{11}$ in the wide and oval coronal part of the root canals; this is an inherent characteristic of the lateral condensation technique ${ }^{8}$.
In the apical portion of the fillings, the highest sensitivity levels were independent of the sealer applied, a result that corroborate the findings of Huybrechts, et al. ${ }^{10}$ (2009). The lower gutta-percha and sealer content at this point of the tapered canal as well as the thick diameter of the simulated void may have resulted in easier detection of defects, a phenomenon that may also have contributed to the absence of statistical difference between groups. The identification of voids in the apical portion of fillings using radiography is important because the apex may harbor bacteria that grow when they receive nutrients from the periapical region or lateral canals, thus compromising the entire treatment ${ }^{17}$.

In this study, root canal fillings performed with the sealer of lower radiopacity (Acroseal ${ }^{\circledR}$ ) were regarded as having better quality (high specificity) compared with fillings performed with the more radiopaque sealer $\left(\mathrm{AH} \text { Plus }{ }^{\mathrm{TM}}\right)^{18,19}$. As a potential explanation of this inconsistency, we suspect that Acroseal has a low flow rate. This property affects the functional thickness of the sealer and may permit better accumulation between the gutta-percha cones ${ }^{22}$, thus increasing the overall radiopacity of root canal fillings ${ }^{9}$ and satisfying examiner expectations regarding filling quality. In this sense, the patterns of sealer distribution through the root canal may depend not only on the physical properties of the sealer, but also on the filling technique applied ${ }^{8,23}$. In this sense, physical properties other than radiopacity seemed to influence, in a different way, the radiographic perception of defective or adequate root canal fillings performed with lateral condensation ${ }^{6}$. Given that only two commercial root canal sealers were tested in this study, the adoption of other sealers with different physical characteristics could generate stronger evidence about the unique influence of radiopacity on the radiographic detection of root canal filling defects.

The result mentioned above provides evidence that radiopacity levels ranked in vitro are not directly related to quality perceptions of laterally condensed fillings on radiographs. Furthermore, the previous assumption that a more radiopaque sealer might yield a better impression of a compact filling ${ }^{4,9}$ does not appear to have scientific support in these cases. In addition to the unsuspected radiographic superimposition caused by guttapercha, the sealer film formed among gutta-percha points may be thinner than that commonly adopted for in vitro tests.

The selection of one radiologist and one endodontist as examiners for this research was based on their radiographic assessment knowledge and on the adoption of the same type of specialists in previous studies ${ }^{1,5,14}$. Until now, no dissonance 
between endodontists and radiologists in the radiographic judgment of root canal fillings has been reported ${ }^{1,5,14}$. In the present study, a difference in sensitivity between these specialists was detected in the assessment of control group fillings (Table 1). Since only one endodontist was compared to one radiologist, it should be clear that this result is not scientifically or statistically powerful. We believe that the radiographic view of minor undesirable voids, which were not superimposed by the nonradiopaque sealer, generated uncertainty in the final decision regarding the presence or absence of empty spaces in the fillings. This uncertainty coupled with poor calibration of examiners before the analysis of images allowed their personal experience and subjective knowledge to guide the diagnostic decision, as reported in other investigations ${ }^{1,5,14}$.

The perception of filling defects by means of radiographic analysis is important but does not necessarily compromise treatment. Voids can be very short or cul-de-sac in nature, therefore not providing pathways for bacteria and toxins that leak from the root canal third ${ }^{20}$. In this way, the identification of filling defects per se does not substantiate the need for retreatment, especially when no other signs or clinical symptoms indicate endodontic failure.

Finally, small filling voids or voids located in buccolingual sites may not be identifiable on periapical radiography. Thus, the results provided in this study suggest that the absence of radiographically identifiable voids in root canal fillings does not ensure they do not exist. For this reason, such evidence should not prohibit treatment revision when signs and symptoms of failure are evident.

\section{CONCLUSIONS}

Within the limitations of this ex vivo study, it was concluded that the type of sealer can affect the observers' ability to detect root canal filling voids during radiographic analysis of upper singlerooted teeth. In addition, this effect seemed not to be related to the in vitro radiopacity of sealers.

\section{ACKNOWLEDGEMENTS}

The authors wish to thank Drs. Cassia Maria Fisher Rubira and Daniela Silva who kindly performed the radiographic evaluations and Dr José Roberto Lauris for statistical advice.

\section{REFERENCES}

1- Akdeniz BG, Soğur E. An ex vivo comparison of conventional and digital radiography for perceived image quality of root fillings. Int Endod J. 2005;38:397-401.
2- American National Standards Institute. American Dental Association. Specification no. 57: Endodontic sealing materials. Chicago; ANSI/ADA; 2000.

3- Baksi Akdeniz BG, Eyüboğlu TF, Şen BH, Erdilek N. The effect of three different sealers on the radiopacity of root fillings in simulated canals. Oral Surg Oral Med Oral Pathol Oral Radiol Endod. 2007;103:138-41.

4- Beyer-Olsen EM, Ørstavik D. Radiopacity of root canal sealers. Oral Surg Oral Med Oral Pathol. 1981;51:320-8.

5- Bhaskaran B, Qualtrough AJ, Rushton VE, Worthington HV, Horner K. A laboratory comparison of three imaging systems for image quality and radiation exposure characteristics. Int Endod J. 2005;38:645-52.

6- Bodanezi A, Munhoz EA, Bernardineli N, Capelozza AL, Moraes IG, Bramante CM. Radiographic analysis of root canal fillings: influence of two sealers on the perception of voids. Braz Dent J. 2010;21:142-7.

7- Chugal NM, Clive JM, Spångberg LS. Endodontic infection: some biologic and treatment factors associated with outcome. Oral Surg Oral Med Oral Pathol Oral Radiol Endod. 2003;96:81-90.

8- Facer SR, Walton RE. Intracanal distribution patterns of sealers after lateral condensation. J Endod. 2003;29:832-4.

9- Gambarini G, Testarelli L, Pongione G, Gerosa R, Gagliani M. Radiographic and rheological properties of a new endodontic sealer. Aust Endod J. 2006;32:31-4.

10- Gorduysus M, Avcu N. Evaluation of the radiopacity of different root canal sealers. Oral Surg Oral Med Oral Pathol Oral Radiol Endod. 2009;108:e135-40.

11- Huybrechts B, Bud M, Bergmans L, Lambrechts P, Jacobs R. Void detection in root fillings using intraoral analogue, intraoral digital and cone beam CT images. Int Endod J. 2009;42:675-85. 12- Kersten HW, Wesselink PR, Thoden van Velzen SK. The diagnostic reliability of the buccal radiograph root canal filling. Int Endod J. 1987;20:20-4.

13- Kositbowornchai S, Hanwachirapong D, Somsopon R, Pirmsinthavee S, Sooksuntisakoonchai N. Ex vivo comparison of digital images with conventional radiographs for detection of simulated voids in root canal filling material. Int Endod J. 2006,39:287-92.

14- Molven O, Halse A, Fristad I. Long-term reliability and observer comparisons in the radiographic diagnosis of periapical disease. Int Endod J. 2002;35:142-7.

15- Nielsen CJ. Effect of scenario and experience on interpretation of mach bands. J Endod. 2001;27:687-91.

16- Sjögren U, Hagglund B, Sundqvist G, Wing K. Factors affecting the long-term results of endodontic treatment. J Endod. 1990;16:498-504.

17- Sundqvist G, Figdor D, Persson S, Sjögren U. Microbiologic analysis of teeth with failed endodontic treatment and the outcome of conservative re-treatment. Oral Surg Oral Med Oral Pathol Oral Radiol Endod. 1998;85:86-93.

18- Tanomaru-Filho M, Jorge EG, Guerreiro-Tanomaru JM, Gonçalves M. Radiopacity evaluation of new root canal filling materials by digitalization of images. J Endod. 2007;33:249-51. 19- Tanomaru-Filho M, Jorge EG, Tanomaru JM, Gonçalves M. Evaluation of the radiopacity of calcium hydroxide- and glassionomer-based root canal sealers. Int Endod J. 2008;41:50-3. 20- Van der Sluis LWM, Wu MK, Wesselink PR. An evaluation of the quality of root fillings in mandibular incisors and maxillary and mandibular canines using different methodologies. J Dent. 2005;33:683-8.

21- Van Nieuwenhuysen JP, Aouar M, D'Hoore W. Retreatment or radiographic monitoring in endodontics. Int Endod J. 1994;27:7581.

22- Weisman MI. A study of the flow rate of ten root canal sealers. Oral Surg Oral Med Oral Pathol. 1970;29:255-61.

23- Wu MK, Özok AR, Wesselink PR. Sealer distribution in root canals obturated by three techniques. Int Endod J. 2000;33:340-5. 